\section{Case Reports in Neurology}

Case Rep Neurol 2020;12:143-148

DOI: 10.1159/000504567

Published online: December 14, 2020 (c) 2020 The Author(s)

Published by S. Karger AG Basel D OPEN www.karger.com/crn

This article is licensed under the Creative Commons Attribution-NonCommercial 4.0 International License (CC BY-NC) (http://www.karger.com/Services/OpenAccessLicense). Usage and distribution for commercial purposes requires written permission.

\title{
Post-Traumatic Carotid Artery Dissection Begins at the Skull Base: A Case Report
}

\author{
Narayanaswamy Venketasubramanian ${ }^{a}$ Pravin Mundada ${ }^{b}$ \\ Amogh Narayan Hegde ${ }^{b}$ Marcus $\operatorname{Tan}^{c}$ Darren $\mathrm{Ng}^{\mathrm{d}}$ \\ aRaffles Neuroscience Centre, Raffles Hospital, Singapore, Singapore; bepartment of \\ Diagnostic Radiology, Raffles Hospital, Singapore, Singapore; 'Raffles Eye Centre, Raffles \\ Hospital, Singapore, Singapore; dRaffles Skin and Aesthetics Centre, Raffles Hospital, \\ Singapore, Singapore
}

\section{Keywords}

Carotid artery · Dissection · Post-traumatic carotid artery dissection · Stroke

\begin{abstract}
Cervical artery dissection is a rare complication of head and neck trauma. Though it is an infrequent cause of ischaemic stroke, it is more common among the young with cerebral ischaemia. The usual location of carotid dissection is just beyond the carotid bulb. We report a case of post-traumatic internal carotid dissection that began at the base of the skull after blunt head trauma from a road traffic accident. The patient is a 25 -year-old right-handed lady who, 2 days after the accident, developed dysphasia and right-sided limb weakness. She had no significant past medical history. Magnetic resonance imaging (MRI) showed acute ischaemic stroke in the internal watershed regions of the left cerebral hemisphere. MR angiogram revealed focal near-occlusion of the left internal carotid artery at the base of the skull just prior to its entry into the petrous temporal bone. There were no skull fractures. She progressed despite anticoagulation. The location of the site of dissection at the base of the skull is likely due to stresses on the carotid intima at this point during flexion-extension-rotation that occurs during head injury, as this is where the internal carotid artery is tethered to the skull. Rapid
\end{abstract}

\begin{tabular}{ll}
\hline & Dr N. Venketasubramanian \\
Raffles Neuroscience Centre \\
& 585 North Bridge Road, \#09-00 Raffles Specialist Centre \\
& Singapore 188770 (Singapore) \\
drnvramani@gmail.com
\end{tabular}




\section{Case Reports in Neurology}

Venketasubramanian et al.: Post-Traumatic Carotid Artery Dissection Begins at the Skull Base: A Case Report

recognition of symptoms of cerebral ischaemia among patients with blunt head trauma is needed to allow prompt investigation and institution of relevant therapies.

\section{Introduction}

Dissection of the cervical arteries account for $15-20 \%$ of strokes among the young, with minor trauma as a potential trigger for the dissection [1]. The most frequent location of the dissection is the cervical portion of the internal carotid artery, just beyond the bulb. We report a patient with stroke due to post-traumatic carotid artery dissection that occurred at the base of the skull just proximal to the entry of the internal carotid artery into the petrous temporal bone.

\section{Case Report}

The patient is a 25 -year-old right-handed lady who was transferred to our hospital a day after she was injured in a road traffic accident. She sustained multiple abrasions to her face and limbs. She had noted an hour of visual loss in her left eye shortly after the accident that improved and changed to occasional "kaleidoscope"-like light pattern in both eyes. There was no history of hypertension, diabetes mellitus, hyperlipidaemia, smoking, heart disease or headaches. Clinical and neurological examination was otherwise normal.

She underwent urgent repair of her complex facial lacerations under general anaesthesia, and debridement and repair of her multiple limb abrasions. On awakening the next day, she was found to have reduced speech and right-sided limb weakness. On neurological examination, she was fully alert and had no gaze deviation but a right inferio-temporal quadrantanopia. She was dysphasic, could only perform up to 2-step commands, but was fluent and could repeat and name objects correctly. There was no clear facial or lingual weakness and no Horner's syndrome. Limb tone and reflexes were reduced in the right upper limb, power was $0 / 5$; the right lower limb had normal tone and reflexes, power was $3 / 5$. Plantar reflex was upgoing on the right, down-going on the left. Left-sided limb examination was normal. Pain sensation was intact. NIHSS score was 10. No bruising was seen over the neck. She did not look Marfanoid, nor were there signs of joint hypermobility or skin hyper-elasticity.

Ophthalmological examination did not reveal any ophthalmological causes for her quadrantanopia, such as vitreous haemorrhage, commotio-retinal or retinal detachment. There was also no papilloedema or optic nerve haemorrhages.

An urgent magnetic resonance imaging (MRI) of the brain with time of flight non-contrast MR angiography (MRA) showed acute ischaemic lesions on the left cortical watershed area, with focal near-occlusion of the left internal carotid artery (LICA) at the base of the skull just proximal to the entry into the petrous temporal bone, with intramural haematoma (Fig. 1). There were no bony fractures.

She was diagnosed to have stroke from carotid dissection and commenced on warfarin and low-dose low-molecular-weight heparin, with concerns that her many abrasions and unknown internal injuries could bleed uncontrollably.

\section{Karger'=}




\section{Case Reports in Neurology}

Despite therapy, she progressed clinically, with loss of verbal output, right lower limb plegia by the next day and a NIHSS score of 16 . Her subsequent clinical status remained unchanged over the succeeding days. Repeat MRI of the brain with time of flight non-contrast MRA showed extension of the left cortical ischaemic lesions, and total LICA occlusion from the origin up to the cavernous segment, with retrograde filling of the distal LICA and collateral flow into the left middle and anterior cerebral arteries (Fig. 2).

She underwent speech and physiotherapy; anticoagulation was maintained. She was transferred to another hospital for further treatment and rehabilitation. NIHSS on discharge, 10 days after stroke onset, was 15.

\section{Discussion}

Cervical artery dissection is a result of a tear in the intima or rupture of the vasa vasorum supplying blood to the arterial wall, leading to bleeding within the tunica media. This leads to separation of the layers of the vessel wall and the creation of a false lumen. The haematoma could expand outwards towards the adventitia (sub-adventitial dissection) that may be accompanied by a dissecting pseudoaneurysm, or inwards towards the intima (subintimal dissection) causing narrowing of the arterial lumen [2]. Our patient's MRA showed a filling defect in the internal carotid artery just proximal to its entry into the petrous temporal bone, consistent with a subintimal dissection.

Risk factors for dissection include hypertension, hypercholesterolaemia, migraine, particularly with aura, hyperhomocysteinaemia, recent infection, certain genetic connective tissue conditions (such as Ehlers-Danlos syndrome, Marfan's syndrome, fibromuscular dysplasia, osteogenesis imperfecta) and minor trauma [2]. Our patient did not have any of the underlying predisposing factors for arterial dissection, except for the trauma. There was no evidence of fibromuscular dysplasia on her MRA. Internal carotid artery dissection occurs in up to $0.86 \%$ among victims of blunt head or neck trauma [3].

The carotid artery may suffer injury anywhere from the common carotid artery to the cavernous sinus [4]. The commonest location of the carotid dissection is just beyond the bulb. This may be due to wall stress increases in the intima in this region due to head movements $[5,6]$. However, in 1 case series, $49.0 \%$ of carotid dissections were only in the distal third of the internal carotid artery, $96.1 \%$ involved the distal two-thirds, with only $3.9 \%$ originating in the proximal one-third [7]. In another study, based on computed tomography, MR or digital subtraction angiography, dissection at segment III (corresponding with the first and second cervical vertebrae) was the most common site $(37.5 \%)$ of carotid artery dissection during trauma, while in spontaneous dissection, segment I (origin of the vessel to the fifth cervical vertebrae) was the most common site (55\%) [8]. In our patient, it was in the distal portion of the extracranial internal carotid artery just proximal to its entry into the petrous temporal bone. The novelty in our case is the demonstration on MRI of the dissection in segment III blood in the arterial wall. The intimal tear, the initial event that led to the dissection, is likely due to injury to the endothelium and inner layers of the arterial wall from hyperextension or rotation of the neck.

Arterial dissection can cause ischaemic stroke either by thrombus forming at the site of injury that then embolises distally or, less frequently, as a result of haemodynamic insufficiency due to severe carotid stenosis or occlusion leading to distal field ischaemia. The brief left-eye visual loss she experienced shortly after the accident may have been due to transient

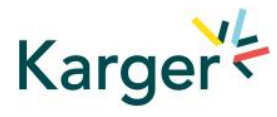




\section{Case Reports in Neurology}

Venketasubramanian et al.: Post-Traumatic Carotid Artery Dissection Begins at the Skull Base: A Case Report

retinal ischaemia due to embolism. The pattern of the subsequent cerebral infarctions suggests haemodynamic mechanisms.

The optimal treatment for secondary prevention of stroke after arterial dissection is still unclear. A recent meta-analysis of smaller trials [9] failed to show superiority of either antiplatelets or anticoagulation over the other. Our patient progressed despite immediate institution of adequate anticoagulation. The American College of Radiology recommends that among those with suspected stroke who developed a new focal neurologic deficit, fixed or worsening, in conjunction with MRI of the head, a non-contrast head MRA and contrast-enhanced neck MRA be performed [10]. A systematic review of 16 studies suggested that endovascular treatment for carotid dissection and concomitant proximal intracranial occlusion, using any or combinations of intra-arterial thrombolytic therapy, angioplasty or stenting, was associated with favourable outcome and successful reperfusion; however, the authors warned that most of the included studies had a high risk of bias [11].

Our case illustrates the rare occurrence of a complication of blunt head and neck trauma. Traumatic carotid dissection more likely occurs at the skull base rather than at the carotid bifurcation due to the twisting sheer forces on the carotid intimal layer during the head flexion-extension-rotation that occurs during head trauma. Rapid recognition of symptoms of cerebral ischaemia is needed to allow prompt investigation and institution of relevant therapies.

\section{Statement of Ethics}

This study was conducted ethically in accordance with the Helsinki Declaration. Informed consent was obtained from the patient and her parents. Our hospital ethics committee has approved this case report.

\section{Conflict of Interest Statement}

The authors have no conflicts of interest to declare.

\section{Funding Sources}

The authors have no funding sources to disclose.

\section{Author Contributions}

Narayanaswamy Venketasubramanian: neurologist, managed the stroke aspects of the patient, wrote the paper.

Pravin Mundada: radiologist, interpreted the scans, selected images for publication, provided critical review of the paper.

Amogh Narayan Hegde: radiologist, interpreted the scans, selected images for publication, provided critical review of the paper.

Marcus Tan: ophthalmologist, managed ocular issues of the patient, provided critical review of the paper.

\section{Karger'=}




\section{Case Reports in Neurology}

\begin{tabular}{l|l}
\hline Case Rep Neurol 2020;12:143-148 \\
\hline DOI: 10.1159/000504567 & $\begin{array}{l}\text { @ 2020 The Author(s). Published by S. Karger AG, Basel } \\
\text { www.karger.com/crn }\end{array}$ \\
\hline
\end{tabular}

Venketasubramanian et al.: Post-Traumatic Carotid Artery Dissection Begins at the Skull Base: A Case Report

Darren Ng: plastic surgeon, primary doctor of the patient and managed the patient's injuries, provided critical review of the paper.

\section{References}

1 Sztajzel R, Perren F, Michel P. [Spontaneous carotid and vertebral dissections]. Rev Med Suisse. 2017 Apr;13(560):900-6.

2 Blum CA, Yaghi S. Cervical Artery Dissection: A Review of the Epidemiology, Pathophysiology, Treatment, and Outcome. Arch Neurosci. 2015 Oct;2(4):e26670.

3 Nedeltchev K, Baumgartner R. Traumatic cervical artery dissection. Front Neurol Neurosci. 2005;20:54-63.

4 Opeskin K. Traumatic carotid artery dissection. Am J Forensic Med Pathol. 1997 Sep;18(3):251-7.

5 Callaghan FM, Luechinger R, Kurtcuoglu V, Sarikaya H, Poulikakos D, Baumgartner RW. Wall stress of the cervical carotid artery in patients with carotid dissection: a case-control study. Am J Physiol Heart Circ Physiol. 2011 Apr;300(4):H1451-8.

6 Caso V, Paciaroni M, Bogousslavsky J. Environmental factors and cervical artery dissection. Front Neurol Neurosci. 2005;20:44-53.

7 Downer J, Nadarajah M, Briggs E, Wrigley P, McAuliffe W. The location of origin of spontaneous extracranial internal carotid artery dissection is adjacent to the skull base. J Med Imaging Radiat Oncol. 2014 Aug;58(4):408-14.

8 Lleva P, Ahluwalia BS, Marks S, Sahni R, Tenner M, Risucci DA, et al. Traumatic and spontaneous carotid and vertebral artery dissection in a level 1 trauma center. J Clin Neurosci. 2012 Aug;19(8):1112-4.

9 Chowdhury MM, Sabbagh CN, Jackson D, Coughlin PA, Ghosh J. Antithrombotic treatment for acute extracranial carotid artery dissections: a meta-analysis. Eur J Vasc Endovasc Surg. 2015 Aug;50(2):148-56.

10 American College of Radiology [Internet]. ACR Appropriateness Criteria. Cerebrovascular Disease. 2016. p. 3. Available from: https://acsearch.acr.org/docs/69478/Narrative/

11 Hoving JW, Marquering HA, Majoie CB. Endovascular treatment in patients with carotid artery dissection and intracranial occlusion: a systematic review. Neuroradiology. 2017 Jul;59(7):641-7.
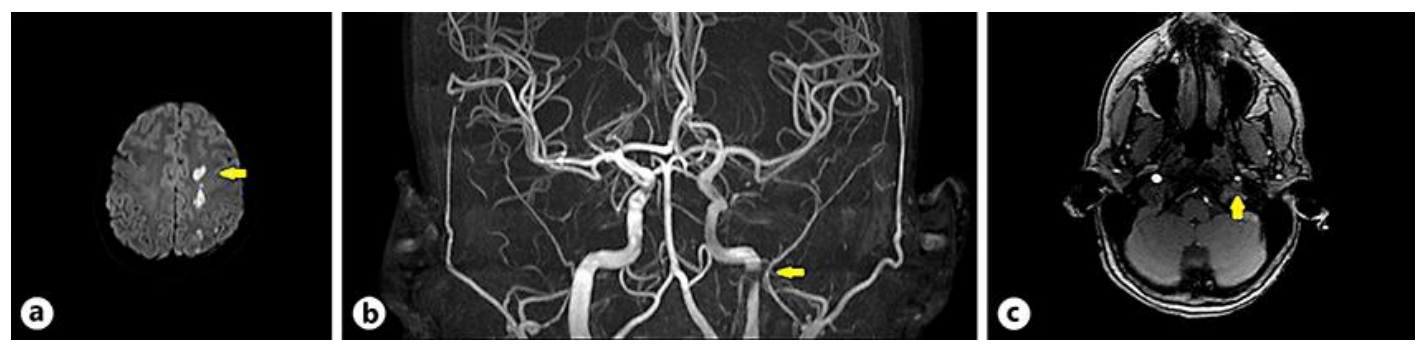

Fig. 1. a MRI of the brain showing diffusion-weighted imaging changes (arrow) of acute ischaemic lesions in the left cortical watershed area. b MRA showing filling defect in the internal carotid artery at the base of the skull just proximal to the entry into the petrous temporal bone (arrow). c MRI of the brain showing intramural haematoma (arrow). 
Case Reports in Neurology
Case Rep Neurol 2020;12:143-148 DOI: $10.1159 / 000504567$ (c) 2020 The Author(s). Published by S. Karger AG, Basel Venketasubramanian et al.: Post-Traumatic Carotid Artery Dissection Begins at the Skull Base: A Case Report
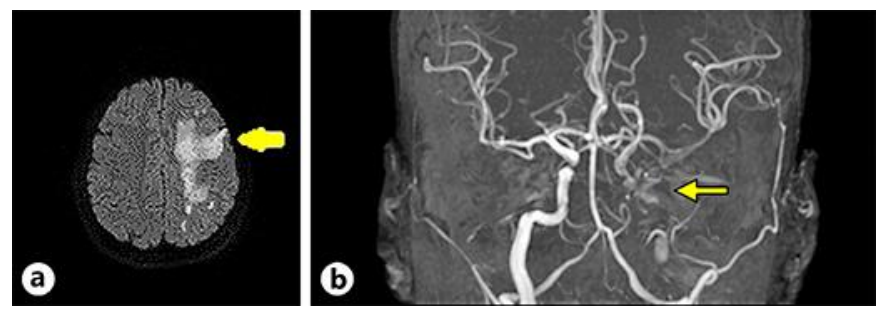

Fig. 2. a MRI of the brain showing extension of the left cortical ischaemic lesions (arrow). b MRA showing total left internal carotid artery occlusion from origin up to the cavernous segment (arrow), with retrograde filling of the distal left internal carotid artery and collateral flow into the left middle and anterior cerebral arteries. 